At one period medical men were afraid to administer any salt, of tin from an idea that arsenic was generally contained in it; and the celebrated chemist, Margraff, affirmed, that he had found a very alarming proportion of arsenic in it. Schultz and Bayer, however, went through a most elaborate inquiry, which dissipated all apprehension. I need not point out to you of what deep importance to us it is to have ascertained this fact accurately, as so much depends in our domestic economy upon the purity of this substance.

The hydrochlorate of tin is the only salt that appears to have much deleterious influence on the human economy; and Orfila relates one case in his "Toxicology," which he learnt from a friend. In this it seems that diarrhoea in some, colic in other's, occurred in a family in which the cook, mistaking this salt for common salt, had used it as such in preparing the dinner. There are many curious facts relating to this metal, which the alchemists called Jupiter, and its salts Jovial; but the most important one is, that Ray directed the attention of philosophers to it, when he was struck with the increase of its weight during calcination; that Boyle endeavoured to ascertain the cause of it, and that Lavoisier finally established the important doctrine, that the oxygen of the air enters into combination with metals, and thus led the way to some of the explanations of the marvellous phenomena which chemistry now so easily and so clearly illustrates to us.

The classical history of tin is peculiarly interesting, more particularly as it is connected with the earliest commerce of this country. The antiquarians have proved to us, that Phonicia must have carried on an intercourse with this island in the earliest days of which mankind has any record. The mineralogist shows that neither in Africa or Asia, except in the East Indies, mines of tin have ever existed, and our happy island was doubtless designated Insulæ Cassiterides, from which cassiteros, or tin, was obtained. The manner in which stream tin, the only ore of that metal, formerly wronght in Cornwall, is described by Pliny, leaves but little doubt that it was obtained from thence. Tin works are carried on there, and this is more used than that of India, although that which is purest comes from Borneo and Malacca.

In the French language there are some interesting memoirs on this metal, to which I must refer you for further information; these are by Baumé, by Macquer, Pelletier, Ronelle, Bayen, and Challard; nor have the Germans been less industrious. I am sorry to say I cannot find you even a very brief catalogue of names of English chemists, who have devoted their attention to the metals in the same complete and useful form.

\section{CONTRIBUTIONS TO PHYSIOLOGY.}

LIFE, ITS PHYSICAL PHENOMENA AND LAWS.

By J. Johnston Kelso, M.D., Lisburn.

Ir was remarked by the celebrated Lord Clarendon, "that there is no art, or science, too difficult for industry to attain. ** It is that only which conducts us through any noble pursuit to a noble end. What we obtain without it is by chance, what we obtain with it is by virtue." Founded as I conceive this principle to be in truth, its fulfil. ment becomes only a matter of time, united to a cautious spirit of induction from facts cognisable to our senses; and if the dis. coveries of physiologists in the science of life have not been commensurate with their labours, the fact is evidently attributable to misdirected efforts to the attainment of a knowledge of the nature of a mere shadow, instead of true practical information; or, to borrow the language of Dr. Prout, " of what the vital principle $i s$, rather than what it does."-(On the Application of Chemistry to Physiology, \&c.) But the more modern philosophers, seeing this practical error of their predecessors, in the same pursuits, have instituted a new order of things; and the physical phenomena of life being more within the scope of human inquiry, are now obtaining that due share of investigation, as regards details, which their importance demands, and which was formerly but too lavishly bestowed in crude conjectures on the nature of the vital essence.

Life, the essence of which has been defined to be an antiseptic principle (Stakl); a principle of self-preservation from destruction (John Hunter, Professor Burns); a principle analogous to electricity (Abernethy, among others); a chemical laboratory, in which there is carried on a multitude of chemical actions for a definitive purpose (Berzelius); the principles of sensibility and contractility (Bichat); the property of certain corporeal combinations, existing for a limited time, and under a determinate form, and in drawing incessantly into their com. position portions of extraneous matter, whose elements they appropriate as parts of their proper stracture (Cuvier); a mo. tion of temporary formation, in which ele. ments remain united, which would separate did life cease, and in which elements separate without the action of caloric (Beclard); may rather, I am inclined to think, be supposed essentially to result from a normal and reciprocal action of the organic functions, and the chief of the animal functions, the brain ; of the circulation of pure oxygenated blood, and of the nervons action; of the function of nutrition and assimilation, and of the chemical changes throughout the body, and of that action.

Without, however, subscribing altogether 
to the correctness of the assertion of $\mathrm{Mr}$. Hunter, "that of all things on the face of the earth definitions are the most cursed," I nevertheless do hold that, if taken for more than they are actually calculated to convey, these become, to say the least, highly detrimental to the advancement not only of physiology, but of all the sciences. Thus the definitions of life, some of which have just been quoted, which ostensibly embrace within their meaning only its essential nature, whether material or immaterial, to the utter exclusion of its physical phenomena and ascertained laws, have, instead of forwarding existing knowledge in this highly interesting department of physiological science, only tended rather to retard it, and are now justly exploded as baseless theories, which, for aught we can positively say, as physical inquirers, may or may not be true. For this principle, like that of gravitation, of attraction, of caloric, \&c., whose existence is only known from its physical phenomena, can hardly, in the nature of things, be included in any definition, however studied or refined, and hence it must, therefore, remain, like those other important principles, by which all matter is more or less influenced, as an ultimate fact in nature, of which we, in all likelihood, shall never know much that is positive or tangible.

On the other hand, those other definitions of life which, leaving ont of account the essentiality of this principle, are solely based upon its physical phenomena, are almost equally unsatisfactory, inasmuch as, in these, reference is only made to some few or more of those more prominent and essential phenomena, or laws of vitality, which, instead of comprehending, as they should, the whole chain, only includes, as it were, just as many links of it. For, in truth, as Dr. Alison observes, "the word life, as commonly used, does not denote an individual fact, nor a simple idea, and cannot, therefore, be defined."-(Outlines of Physiology.) "While the word life," says Dr. Elliotson, "should be regarded like the word attraction, or repulsion, as merely the expression of a fact, being in this point of view only definable as any other expression."-(Human Physiology.)

The phenomena of life, which are as much apparent in the least imaginable part of animal matter which we can separate as in the whole (Hunter), are more or less complex, not only in the different classes of animals, up to those highest in the scale of organisation, as man, but also in the latter, at the different phases of his structural development. Thus the life of the ovum which, previously to its being impressed with the stimulus of vivification, bears, in some respects, a close resemblance to a vegetable seed, differs as essentially, in degree, from the life of the foetus in the different stages of its corporeal evolution, as the life of the latter does from the same being subsequently to the period of its taking on an independent existence. This, it is evident, is a legitimate sequence of the different states of the organisation at the different periods of our existence; the superaddition of every new organ, or structure, in the ascending Iadder of animal matter to comparative perfectibility, giving rise, as it must do, at the same time, to corresponding new vital phenomena, or particular kinds of action; for, in all organised bodies, and daring the whole course of their life, the latter are in an exact relation to the state of the former. And it was remarked by the illastrious Beclard, "that organisation and life are in such strict connection, that they may be considered each as a necessary condition of the other, the one alivays supposing the other."-(Elements d'Anatomie Generale.)

It is to the genius of Mr. Hunter that we are indebted for the idea, that life is as simple in man as in the most simple animal, and is reducible to one simple property in every animal; its phenomena being, in his opinion, modifications of this property, simply as the result of differences in the organised apparatus, through which it manifests its defects. (Works by Palmer.) In favour of this view which, although difficult of direct proof, is nevertheless highly probable, reference has been made by a recent authority to the varions powers of common matter. Thus, according to him, the different kinds of attraction has, and, in my opinion, very properly, been considered as modifications of a higher principle, and magnetism, common electricity, and galvanism, have, with equal probability, been supposed to proceed from the same source, or, at least, are essentially identical. The same, there is good reason for believing, is the case in regard to the powers of life. This idea, however, of the unity of the vital principle is a complex idea, but its physical phenomena can no more be considered as effects of different and distinct principles, than these can, unless in an abstract sense, be separated from each other.

And here I would observe, that action may be correctly considered as the essential condition of all those phenomena, the aggregate of which constitute what is called life. Vital action is modified according to the form and composition of the organic parts; and whenever action is changed, it is the result of some appreciable physical change, or alteration, of the organisation of those parts through which it manifests iis efrects; modification of action, as a general rule, always arising from a modification of composition of the part. It is this actic $n$ which effects the absorption of the nutritious elements, which are to be appropriated to the growth and maintenance of the orgar $s$ and physical structures of the body, pro- 
duces the circulation of the blood, and its exposure to the influence of the atmospheric air, through the medium of the beautifal mechanism of the respiratory apparatus, the circulation of the various seereted fluids to their proper destinations, \& c.; in a word, which maintains that unintermitting motion which is found to exist in most of the solids, and, through these, in the fluids of the body during life. The phenomena of innervation even do not appear to be produced to its entire exclusion, for there is good reason for believing, with the late M. Beclard, that these essentially result from some kind of molecular action, or motion, in the nervous substance, which produces sensation, as well as those other effects referable to nervous action. If future investigation may establish this, which is at present only problematical, and were I permitted to hazard a conjecture where everything is intricate and obscure, I would decidedly say, that life is the principle of action, or contractility; the modifications of action, from differences of the organic parts, producing the various phenomena which are designated by the term vital.

The laws regulating these phenomena may be classed under the following heads :-

1. Vital contractions, by which not only the visible movements of living animals, but also those internal and generally involuntary motions in their organisation, are mainly effected. These contractions, or motions, primarily commence with the successive evolution of the several organs and tissues, and terminate only in the death of the animal.

2. Vital attractions, by which the nutritious elements are, so to speak, selected from the general mass of the ingesta, \&c., to become assimilated with the blood, and afterwards depesited from this fluid, in the perpetual rounds of the circulation, in all the organs and parts, so as to effect their grow th and maintain their physical structure.

3. Vital repulsion, by which those particles of animal matter, which have fulfilled their especial purposes in the economy, are dislodged from their temporary location, to be carried away in the torrent of the circulation, and expelled the system. It is, I apprehend, this power, infuencing masses of organised matter, which proves the only proper antagonism of vital contractility .

4. Nertous infuence, by which not only " the physical changes in living animals are placed in connection with mental phenomena, and subjected to the control of mental acts" (Dr. Alisen), but also, especially in those animals in which the nervous system is most developed, so influence those changes in the blood, as well as in the livisg solids of their bodies, as to subject all, or almost all of them to its extraordinary powers. And here, it is to be observed, I cannot but concur with Beclard, who entirely opposes the limitation of innervation (as Dr.Alison here does, with many other's), to mental ope. rations exclnsivelv, for it indisputably holds in subjection to it, directly or indirectly, all the phenomena of life. This influence of the nervous system is the more marked the farther the individual is removed from the foetal state, and the more developed and perfect that system is in him.

Lisburn, Feb. 11, 1833.

(To be continued.)

\section{LARYNGISMUS STRIDULUS.}

To the Edilor of THe LANCET.

SIr:--If you will give insertion to the following remarks, on the Crowing Inspiration of Children, in your valuable Journal, you will oblige yours,

W. H. Hodning, M.R.C.S., \&c.

67, Gloucester-place, I'ortman-square, February 27, 1338.

The crowing inspiration of children is a most interesting affection. Simple in its origin, if not arrested in its progress it be. comes a complicated and often an unman. ageable disease; though it has lately received much professional notice, and attracted the attention of some of our highest authorities, yet, strange to say, there is still a difference of opinion whether this peculiar malady is really a disease or a symptom, and the crowing inspiration the result of partlysis or spasm.

It has been called by different writers " chronic cough," " croupy convulsions," or the "crowing disease;" is especially an affection of childhood, and is sonetimes so insidious in its approach as to excite scarcely any attention till it has assumed a formidable character.

Perhaps the mother or nurse is first struck by the child suddenly awaking in a state of alarm and agitation, stiff, and struggling for breath, and, after repeated efforts, reco. vering with difficulty, and with a long peculiar inspiration, resembling the early crowing of a young cock, which generally occurs after the first sleep. This symptom, in its slightest form, may be overlooked, and, perhaps, slight squinting may be the first indication of something wrong. To this may succeed contractions of the hands, so that the thumb is fixed in the palm, and the toes are firmly bent towards the soles of the feet, and as the disease advances, strangury, tenesmus, confirmed strabismus, general convulsions, and death.

The croupy sound, from which the disease derives its name, arises from functional derangement in the nerves supplying the glottis; but the cause of this is the point on which so much discrepancy exists.

Dr. Clarke has ascribed it to organic mis. chief in the brain itself and giyen it a de, 